\title{
Aplicação de Índices Morfométricos para Análise Geomorfológica e Neotectônica da Bacia do Rio Marés - PB, Brasil
}

\author{
Morphometrics Indices Application for Geomorphologic and Neotectonic Analysis on \\ The Marés River Basin - PB, Brazil.
}

Aplicación de índices morfométricos para analisis geomorfológica y neotectónica en la cuenca del Río Marés - PB, Brasil.

\author{
Tamires Silva Barbosa ${ }^{1}$ \\ Max Furrier ${ }^{2}$
}

Recebido em: 16/04/2016. Aprovado em: 10/04/2017.

\begin{abstract}
RESUMO: Os estudos morfométricos e neotectônicos na bacia do rio Marés se justificam pelo fato da mesma estar situada sobre uma única litologia - a Formação Barreiras, e apresentar mudanças ao longo do perfil longitudinal, não justificáveis pelos fatores climáticos ou litológicos. Apesar de não possuir volume de água significativo em seu canal principal, este tem entalhado seu vale significativamente, apontando para a possível influência neotectônica na área. Para análise da bacia foram utilizados: a carta topográfica Santa Rita na escala 1:25.000 e o software Spring 5.2, para a confecção dos mapas temáticos e execução dos cálculos morfométricos. Os valores obtidos como resultado e as características morfológicas da bacia apontam para a influência de atividade tectônica recente sobre a área.
\end{abstract}

Palavras-Chave: Morfometria; Neotectônica; Formação Barreiras; Bacia hidrográfica.

ABSTRACT: Neotectonic and morphometric studies in Marés River watershed are justified by the fact that it is situated on a single lithology - Barreiras Formation, and show changes along the longitudinal profile, not justified by climatic or lithologic factors. While not possessing significant volume of water in the main river channel, it has grooved its valley significantly, pointing to a possible neotectonic influence in the area. For analysis of the watershed were used: a topographic map in scale 1:25,000 Santa Rita and the Spring 5.2 software, for the making of thematic maps and execution of morphometric index. The values obtained and the morphological characteristics of the basin indicated the influence of recent tectonic activity of the area.

Keywords: Morphometry. Neotectonic. Barreiras Formation. Watershed.

RESUMEN: Los estudios morfométricos y neotectónicos en la cuenca del río Marés son justificados por el factor de dicha cuenca estar ubicada sobre una misma litología - la Formación Barreiras, y presentar cambios a en lo largo del perfil longitudinal, no justificables por los factores climáticos o litológicos. Mismo que ésta cuenca no posee volumen de agua significativo en su cauche principal, este tiene tallado su vale significativamente, apuntando para la posible influencia neotectónica en el área. Para análisis de ésta cuenca fueran utilizados: la plancha topográfica Santa Rita en escala 1:25.000 y el software Spring 5.2, para la confección de mapas temáticos y la ejecución de cálculos morfométricos. Los valores obtenidos como resultado y las características morfológicas de la cuenca apuntan para la influencia de actividades tectónicas recientes en el área.

Palabras Clave: Morfometría. Neotectónica. Formación Barreiras. Cuenca hidrográfica. 


\section{INTRODUÇÃO}

A aplicação de índices morfométricos proposta para este estudo tem como objetivo a análise geomorfológica da bacia hidrográfica do rio Marés, localizada entre os municípios de Santa Rita, Bayeux e João Pessoa, para que se torne viável a verificação da possível atuação de atividades tectônicas recentes sobre o modelado atual, no litoral do estado da Paraíba, Brasil.

Os índices morfométricos utilizados neste trabalho são os índices Relação declividadeextensão (RDE), conhecido como índice SL (Relação Slope vs. Lenght), que é um indicador sensível de mudanças na declividade do canal fluvial, que podem estar associadas a desembocaduras de tributários, a diferentes resistências à erosão hidráulica do substrato rochoso e/ou à atividade tectônica; o Razão Fundo-Altura de Vale (RFAV), também descrito por alguns autores como índice VF (Valley floor), que distingue vales que possuem superfície ampla no fundo de vales estreitos; e o Fator Assimétrico (FA), que avalia a existência de inclinações tectônicas em escala de bacia de drenagem.

Além dos índices morfométricos citados, serão aplicados outros parâmetros morfométricos, tais como: hierarquia fluvial, cálculo da área da bacia, número de canais, índice de rugosidade topográfica, densidade de drenagem, amplitude altimétrica e densidade hidrográfica. Estes parâmetros ampliarão as informações morfométricas acerca da bacia em estudo.

A caracterização geomorfológica de uma área permite conhecer os potenciais naturais existentes nela, facilitando a identificação de áreas de risco de ocupação, ambientes frágeis, impactos ambientais, interferência antrópica e a dinâmica da evolução natural da paisagem, daí se tem a relevância dos estudos geomorfológicos na relação homem-meio.

Existem diferentes maneiras para avaliar a influência neotectônica sobre determinadas áreas, entretanto, selecionou-se para esta análise um elemento do meio físico que se constitui em um processo morfogenético dos mais ativos na esculturação da paisagem terrestre - a bacia hidrográfica.

A bacia hidrográfica representa um sistema facilmente afetado pelas condições climáticas e estruturais, sendo, então, importante testemunho dos processos dinâmicos da Terra. Os aspectos morfométricos das bacias conjeturam os principais fatores responsáveis pelo desenvolvimento do modelado.

A identificação de evidências de atividade neotectônica em terrenos do interior continental, que é o caso da bacia em estudo localizada à retaguarda do litoral, onde o registro da sismicidade seja pobre, ainda pode ser classificada como um esforço heurístico. Nesse sentido, as técnicas morfométricas que exploram atributos relacionados aos perfis ou ao traçado dos cursos d'água apresentam um potencial relativamente elevado para a detecção e a avaliação de deformações. 
Para apoiar a análise morfométrica e geomorfológica foram elaborados produtos cartográficos em ambiente SIG (Sistema de Informação Geográfica), como cartas temáticas de altimetria e declividade, a partir das curvas de nível e pontos cotados digitalizados e vetorizados da carta topográfica Santa Rita 1:25.000. Foram analisadas nestas cartas, as possíveis relações entre as feições geomorfológicas atuais, os padrões da rede de drenagem e a tectônica cenozoica regional nos Tabuleiros Litorâneos.

\section{Área de estudo}

A bacia do rio Marés pode ser encontrada em sua totalidade dentro dos limites da carta topográfica Santa Rita 1:25.000 (SB.25-Y-C-III-1-SO). Ela se localiza à retaguarda do Litoral Paraibano, convergindo para o rio Sanhauá, afluente do rio Paraíba, Nordeste do Brasil.

O rio Marés corta os municípios de Santa Rita, Bayeux e João Pessoa, fazendo parte da microrregião de João Pessoa e Mesorregião do Litoral da Paraíba. Essa bacia é composta por 19 canais, possuindo $28,029 \mathrm{~km}^{2}$ de área e perímetro de 24,885 km (Figura 1).

Figura 1 - Localização da área da bacia do rio Marés.

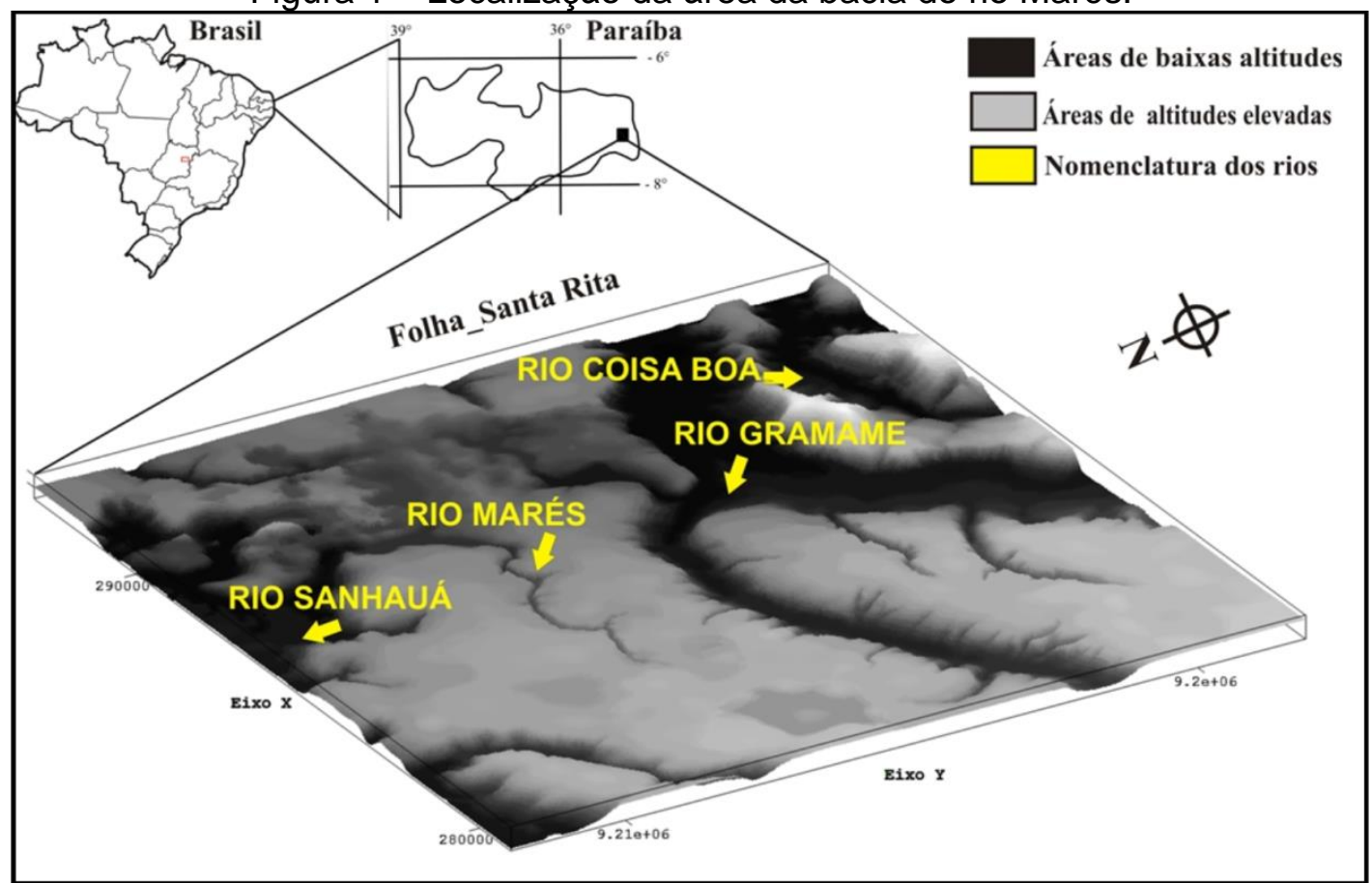

Fonte: Elaborado a partir da vetorização da carta topográfica Santa Rita 1:25.000 (SUDENE,1974) e tratamento dos dados no SIG Spring 5.2. 
Aplicação de Índices Morfométricos para Análise Geomorfológica e Neotectônica da Bacia do Rio...

O clima atuante é o tropical úmido, e as médias das temperaturas anuais situam-se em torno de $25^{\circ} \mathrm{C}$, tendo índices pluviométricos que oscilam entre 1500 e $1700 \mathrm{~mm}$ (MELO, 2003).

A estrutura geológica sobre a qual a bacia do rio Marés se encontra corresponde às rochas que compõem a bacia sedimentar marginal Paraíba. Tendo embasamento cristalino Pré-Cambriano, sobreposto pelas formações do Grupo Paraíba - Beberibe, Gramame e Maria Farinha.

Capeando o Grupo Paraíba está a Formação Barreiras, essa Formação é uma unidade litoestratigráfica de idade miocênica, que se constitui em um conjunto de rochas sedimentares mal consolidadas que se encontram localizadas em faixa que vai desde o estado do Amapá até o norte do Rio de Janeiro, dispõe-se em camadas discordantes sobre embasamento cristalino e bacias sedimentares marginais (ARAI, 2006). Sobre a Formação Barreiras são esculpidos os Baixos Planaltos Costeiros ou Tabuleiros Litorâneos, que é a principal unidade Geomorfológica da área da bacia do rio Marés.

\section{METODOLOGIA}

Para o estudo da bacia hidrográfica, foi utilizada como ferramenta base, a carta topográfica Santa Rita 1:25.000 (SB.25-Y-C-III-1-SO) desenvolvida pela SUDENE (1974). A escolha do uso da carta topográfica e não de imagens SRTM se deu pelo fato de que para tal estudo é necessário a correta e precisa interpolação das curvas de nível.

A vetorização de cartas topográficas na escala 1:25.000 resulta em produtos cartográficos finais mais fidedignos, já que essas cartas topográficas foram produzidas através de extenso aerolevantamento e posterior aerotriangulação através de pontos cotados topograficamente com equipe em solo. Embora, esta técnica de produção cartográfica seja extremamente onerosa, produziu farta documentação e de excelente qualidade para a Borda Oriental do Nordeste Brasileiro.

A vetorização de curvas de nível de cartas topográficas na escala 1:25.000, embora seja árdua e trabalhosa, refletiu em produtos cartográficos mais confiáveis quando comparados a realidade da área verificada in loco. Portanto, para a escala adotada e para a proposta deste trabalho, a vetorização das cartas topográficas e a modelagem dos dados extraídos utilizando o software Spring atenderam plenamente os objetivos propostos.

Sendo assim, a carta foi, primeiramente, digitalizada e vetorizada manualmente, e depois foram trabalhados em ambiente SIG. O SIG selecionado para este estudo foi o Spring, devido ao fato de ser um software gratuito e de fácil manejo, não acarretando em custos, mas que supriu todas as necessidades para o tema central deste trabalho que é a averiguação de evidência de neotectônica em bacia hidrográfica de pequeno porte. 
Os produtos vetoriais foram exportados para o Spring, onde se criou um banco de dados para a análise qualitativa e quantitativa da bacia hidrográfica em estudo. Os cálculos morfométricos foram efetuados na bacia através da ferramenta do Spring 5.2 - "MNT > Operações métricas". E a geração do Modelo Numérico do Terreno permitiu a produção das cartas temáticas de hipsometria e declividade.

Para a aplicação do índice RDE (Relação Declividade-Extensão), elege-se o rio de

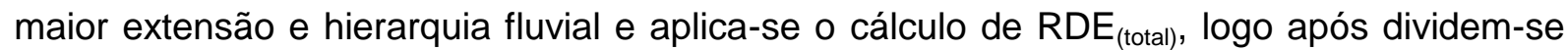
os seguimentos do rio em tamanhos semelhantes e calcula-se o $\operatorname{RDE}_{(\text {trecho) }}$ em cada um dos seguimentos.

Conforme o valor final, resultante do $\mathrm{RDE}_{\text {(total), }}$ afirma-se se há ou não anomalias no rio em questão, tendo como referência o valor 2, se o resultado for maior que 2 existem anomalias e podem ser constatadas atividades tectônicas recentes.

Conforme Martinez (2005), as fórmulas a serem utilizadas para os cálculos de ambos são, respectivamente:

$$
\begin{aligned}
& R D E(\text { total })=\left(\frac{\Delta H}{\operatorname{Ln} L}\right) \\
& R D E(\text { trecho })=\left(\frac{\Delta H}{\Delta L}\right) * L
\end{aligned}
$$

Onde, no RDE (total):

$\Delta H$ é a diferença altimétrica entre a cota localizada a cabeceira do rio e a cota localizada na foz do mesmo (m); e

$L n L$ é o logaritmo natural da extensão total do curso de água (m).

E no RDE (tracho):

$\Delta H$ é a diferença altimétrica entre dois pontos selecionados no curso de água $(\mathrm{m})$;

$\Delta L$ é o comprimento sinuoso do trecho analisado $(\mathrm{m})$; e

$L$ corresponde à extensão total (em linha reta) que vai da nascente do canal até o ponto final do trecho para onde o índice RDE está sendo calculado $(\mathrm{m})$.

Os valores das cotas da nascente, foz e trechos do rio foram obtidos a partir do modelo digital de elevação do terreno, no software SPRING 5.2.

A técnica do RFAV, propalada também como VF (Valley floor), é balizada exclusivamente para áreas fluviais e consiste na medição da altura dos divisores de água do vale (BARBOSA \& FURRIER, 2011). Conforme Bull \& Mcfadden (1977) segundo Andrades Filho (2010), este índice é definido pela seguinte equação: 


$$
R F A V=2 \frac{L f v}{\{(E d e-E f v)+(E d d-E f v)\}}
$$

Onde:

O elemento RFAV representa a razão entre a largura do fundo e a elevação do vale;

Lfv diz respeito ao valor da largura do fundo de vale;

Ede é a elevação do divisor esquerdo do vale;

Edd corresponde à elevação do divisor direito do vale; e

Efv é o valor da média de elevação do fundo do vale.

Para a aplicação deste índice é recomendável selecionar alguns perfis que cortem o canal de maior expressão dentro da bacia, efetuando cortes transversais ao vale, escolhidos em locais previamente determinados. Em seguida os valores encontrados através das operações métricas do software Spring 5.2 e do modelo de elevação do terreno, são lançados na fórmula e então se calcula o índice RFAV.

O valor de referência para o índice RFAV é 1, quanto maior que 1 for o valor resultante da equação do RFAV, mais amplo é o vale em questão e menor é a probabilidade de ocorrência de neotectônica.

Para efetivar o índice de Fator Assimétrico utilizou-se a técnica proposta por Hare e Gardner (1985) conforme Rubin (2003), para eles, o FA é indicado para áreas onde os falhamentos recentes são pobremente expostos ou estão mascarados, e tem como fundamentação básica o fato de a assimetria das bacias ser resultante da migração ortogonal a seu eixo, consequência do tectonismo e/ou de processos aluviais internos.

Segundo Andrades Filho (2010), o FA é definido pela fórmula a seguir, onde Ad é a medida da área direita da bacia e At corresponde à medida da área total da bacia de drenagem:

$$
F A=100\left(\frac{A d}{A t}\right)
$$

O fator de assimetria correspondente a pouco ou nenhum tectonismo produz um valor numérico próximo a 50 , ao passo que valores menores que 50 correspondem a um basculamento da margem direita do curso d'água. Valores superiores a 50 indicam basculamento da margem esquerda (SALAMUNI, 1998 segundo RUBIN, 2003).

Através das ferramentas de edição vetorial do Spring 5.2, foi possível delimitar tanto a área total da bacia quanto a margem direita da mesma. E, através da ferramenta "operações métricas", obtiveram-se os valores de Ad (área da margem direita) e At (área total da bacia). 
Após os cálculos de área efetua-se o FA, substituindo os valores encontrados na dada fórmula.

\section{RESULTADOS E DISCUSSÕES}

\section{Parâmetros Morfométricos}

$\mathrm{Na}$ análise da hierarquia fluvial da bacia do rio Marés, utilizou-se o sistema proposto por Strahler em 1952, o qual entende que os menores canais, sem tributários, são considerados como de primeira ordem; os canais de segunda ordem surgem da confluência de dois canais de primeira ordem, e só recebem afluentes de primeira ordem; os canais de terceira ordem surgem da confluência de dois canais de segunda ordem, podendo receber afluentes de primeira e segunda ordem, e assim sucessivamente (CHRISTOFOLETTI, 1980).

Sendo assim, a bacia hidrográfica do rio Marés é uma bacia de $3^{\underline{a}}$ ordem, compondo uma área de $28,029 \mathrm{~km}^{2}$, contendo 19 canais, dos quais 15 são de $1^{\text {a }}$ ordem, 3 são de $2^{\underline{a}}$ ordem e 1 é de $3^{\text {a }}$ ordem, sendo este último o rio principal. Para determinar o índice de rugosidade da bacia, utilizou-se a seguinte fórmula:

$$
I r=H * D d
$$

Onde Ir corresponde ao índice de rugosidade topográfica, $H$ à amplitude altimétrica dada em metros, e Dd à densidade de drenagem dada em $\mathrm{km}\left(\mathrm{km}^{2}\right)^{-1}$. O índice de rugosidade combina informações pertinentes à amplitude topográfica e à densidade de drenagem (SILVA et al., 2003). No caso da bacia do rio Marés, o valor do índice de rugosidade (Ir) foi estimado em 59,26.

Christofoletti (1980) cita que os valores extremamente altos do Ir ocorrem quando a densidade de drenagem e amplitude altimétrica se mantém altas, ou seja, em regiões onde as vertentes são íngremes e longas.

A bacia em estudo não chega a ter grandes cotas de altitude por estar sobre os baixos planaltos costeiros, que chegam a ter apenas $150 \mathrm{~m}$ de altitude, e também não possui alta densidade de drenagem, entretanto, o entalhe do rio principal é bastante eminente.

A densidade hidrográfica $(D h)$ e de drenagem $(D d)$ da bacia foram calculadas levando em consideração o número de cursos d'água, o comprimento total dos canais e a área da bacia. As fórmulas utilizadas para obtê-las foram respectivamente:

$$
D h=\frac{N}{A}
$$




$$
D d=\frac{L}{A}
$$

Sendo "N" o número total de rios, "A" a área da bacia e "L" o comprimento total dos

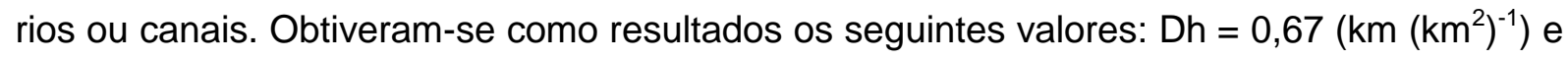
$\mathrm{Dd}=0,83\left(\mathrm{~km}\left(\mathrm{~km}^{2}\right)^{-1}\right)$, mostrando, assim, tratar-se de uma bacia de baixas densidades, ou seja, é uma bacia com número de canais e tamanho dos mesmos relativamente reduzidos. $\mathrm{Na}$ Tabela 1 pode-se verificar um resumo dos valores obtidos com a aplicação dos parâmetros morfométricos.

Tabela 1 - Parâmetros morfométricos utilizados na bacia do rio Marés

\begin{tabular}{cc}
\hline Parâmetros Morfométricos & Valores Obtidos \\
\hline Hierarquia Fluvial & $3^{\text {a }}$ Ordem \\
Índice de Rugosidade & 59,26 \\
Amplitude Altimétrica & $71 \mathrm{~m}$ \\
Densidade Hidrográfica & $0,67\left(\mathrm{~km}^{2}\left(\mathrm{~km}^{2}\right)^{-1}\right)$ \\
Densidade de Drenagem & $0,83\left(\mathrm{~km}^{2}\left(\mathrm{~km}^{2}\right)^{-1}\right)$ \\
Área da Bacia & $28,029 \mathrm{~km}^{2}$ \\
Número de Canais & 19 canais \\
\hline
\end{tabular}

Fonte: Pesquisa direta (2013).

\section{Hipsometria e Declividade}

A carta de hipsometria indica os níveis de altitude de determinada área, unindo os pontos de altitude semelhante, transformando a representação do terreno original em faixas de classes temáticas, que identificam em que altitude estão dispostos os diversos compartimentos que compõem a área.

O mapa de altimetria da bacia do rio Marés (Figura 2) indica que o rio principal da bacia nasce numa altitude média de 60 a $80 \mathrm{~m}$, com a montante escavando o tabuleiro costeiro e a jusante alcançando a planície fluvial do rio Sanhauá. A maior parte do vale do rio se encontra encaixado em 40 a $60 \mathrm{~m}$ de altitude, tendo os menores níveis de altitude após o açude Marés, quando se aproxima à jusante.

A média geral de altitudes da bacia é de $71 \mathrm{~m}$, tendo, nas imediações mais próximas do vale, altitudes que variam de 50 a $40 \mathrm{~m}$, e um vale que apresenta desníveis de até $20 \mathrm{~m}$.

A carta de declividade ou clinográfica aponta a porcentagem da inclinação dos terrenos em determinada área. Essa carta é importante principalmente para demonstrar ocupações ou usos irregulares em declividades inapropriadas. A definição das classes de declividades usadas neste trabalho foi baseada em Herz e De Biasi (1989), que amarraram essas classes a limites usados internacionalmente, bem como a trabalhos desenvolvidos por institutos de pesquisa nacionais e a leis vigentes no Brasil. Essas classes foram especificadas da seguinte forma: 
$\square<12 \%$ : Faixa que define o limite máximo para o emprego de mecanização na agricultura;

$\square 12$ - 30\%: A Lei Federal № 6.766/1979 limita em 30\% de declividade a urbanização sem restrições;

30 - 47\%: A Lei Federal o 4.771/1965 (Código Florestal) limita em 47\% de declividade o corte raso da vegetação;

$\square 47$ - 100\%: Nesse intervalo de declividade, o Código Florestal proíbe a derrubada de floresta sem um regime de utilização racional que vise a rendimentos permanentes;

$\square$ 100\%: É considerada, pelo Código Florestal, área de preservação permanente, apenas sendo admitida a supressão total ou parcial da vegetação com prévia autorização do Poder Público Federal, quando for necessária a execução de obras, planos, atividades ou projetos de utilidade pública ou interesse social.

Figura 2 - Mapa hipsométrico da bacia do rio Marés.

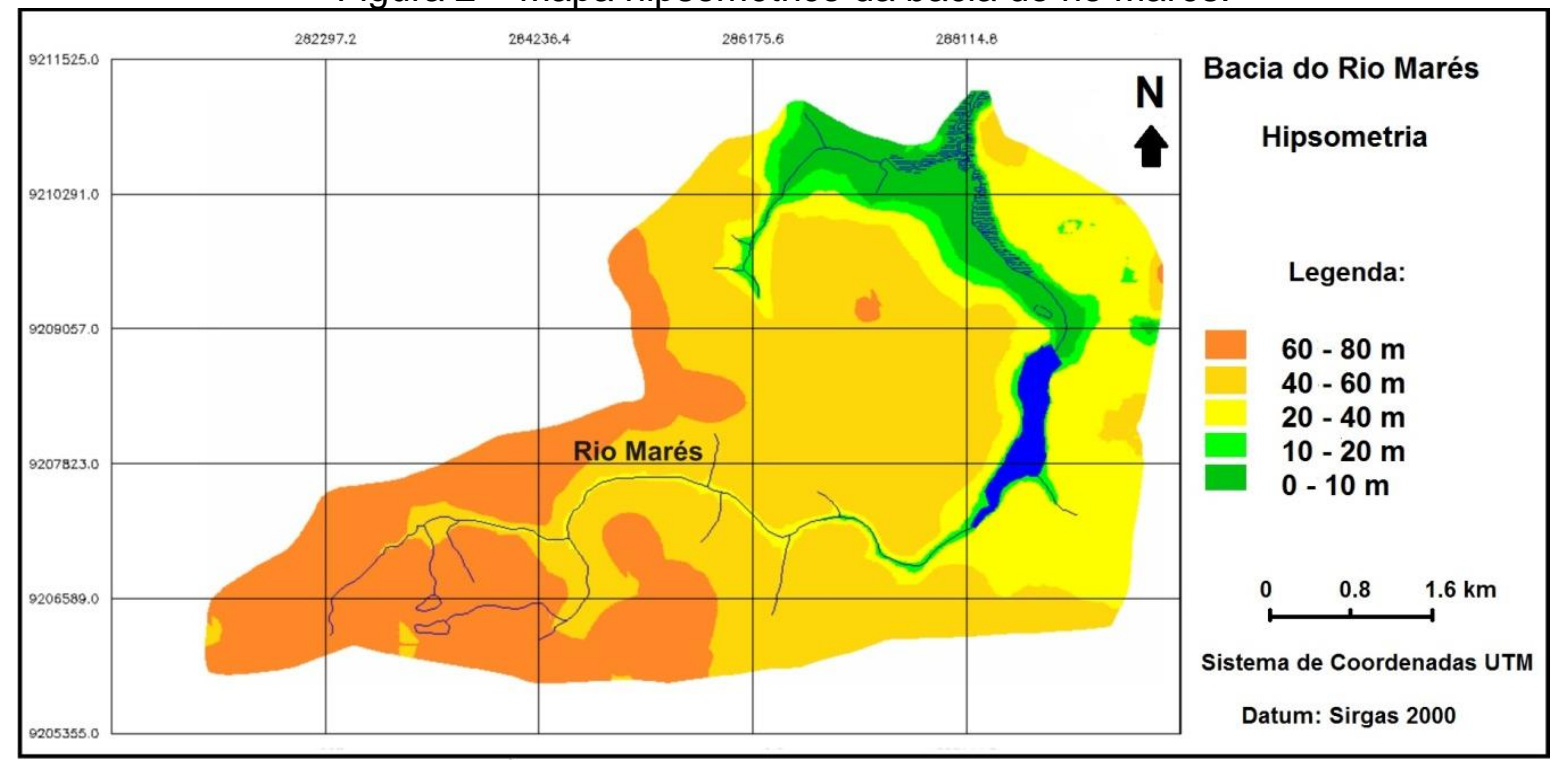

Fonte: Elaborado a partir da vetorização da carta topográfica Santa Rita 1:25.000 (SUDENE,1974) e tratamento dos dados no SIG Spring 5.2.

A área da bacia do rio Marés tem predomínio de declividade entre 0 e $12 \%$, nove de suas dez nascentes encontram-se nessa faixa de declividade, esse valor se justifica por essa ser uma área com morfologia tabular plana a pouco ondulada. Segundo a classificação acima, nessa faixa de declividade é permitido o uso da mecanização agrícola. Devido ao intenso crescimento da agricultura e da urbanização nessa faixa de declividade, das dez nascentes dos rios da bacia, as quais em 1974 se encontravam todas preservadas, em 2008 apenas uma continuava preservada em todo o seu entorno, conforme a Resolução Conama no 303 (CARRILHO et al., 2008). 
As demais faixas de declividade pouco se apresentam, tendo predomínio de 12 a 30\% nas imediações do vale, onde se encontram algumas granjas, pequenas propriedades e conjuntos habitacionais, como é o caso do bairro Heitel Santiago na cidade de Santa Rita, que chega até a margem do vale do rio, correspondendo à classificação de Herz e De Biasi (1989), que limita em 30\% de declividade a urbanização sem restrições. Somente alguns trechos mais próximos ao canal do rio principal possuem declividades que vão de 47 a $100 \%$ (Figura 3).

Figura 3 - Mapa de Declividade da bacia do rio Marés.

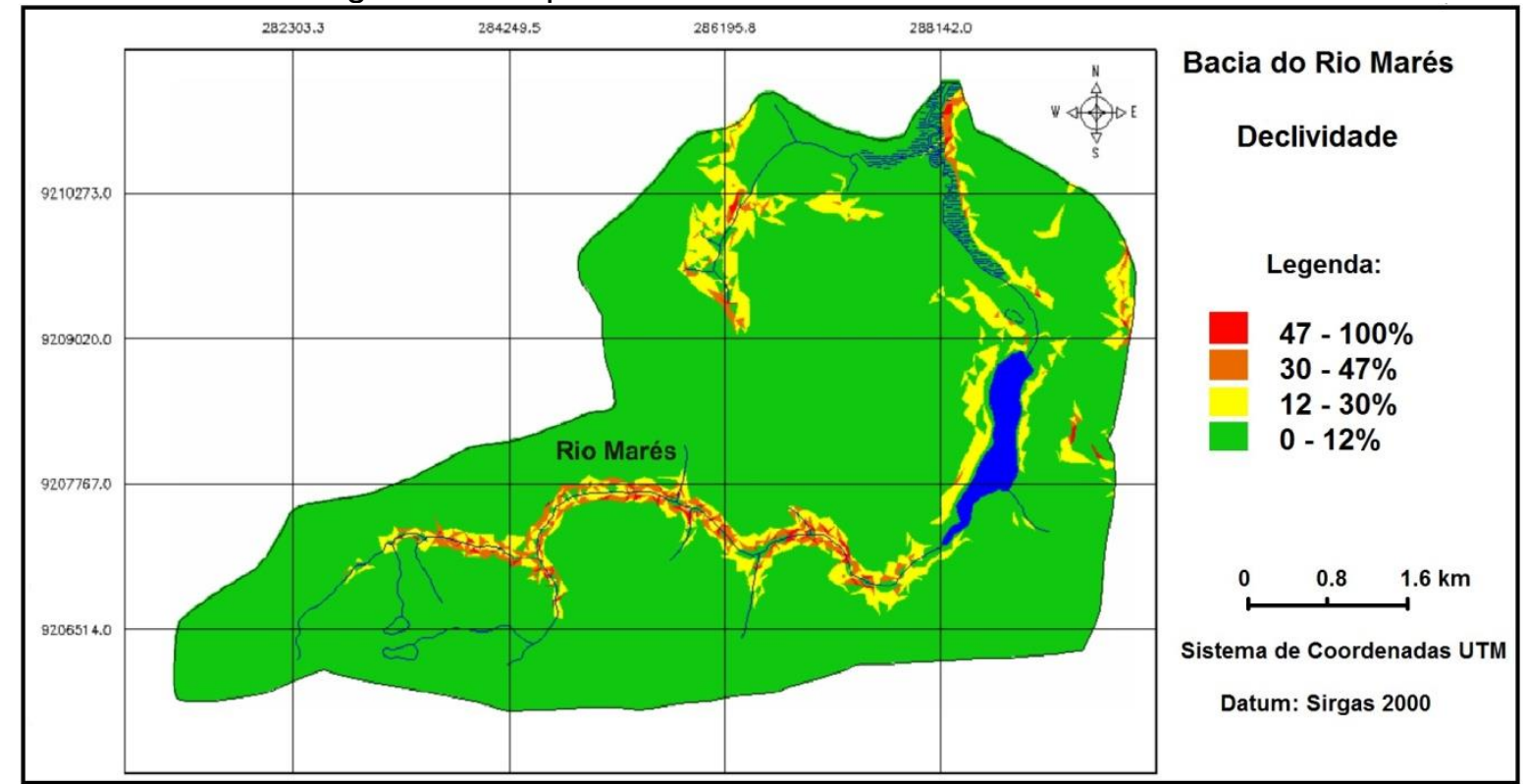

Fonte: Elaborado a partir da vetorização da carta topográfica Santa Rita 1:25.000 (SUDENE,1974) e tratamento dos dados no SIG Spring 5.2.

\section{APLICAÇÃO DOS ÍNDICES MORFOMÉTRICOS}

\section{Índice Relação Declividade-Extensão (RDE)}

Existem duas formas de aplicação do índice RDE: o RDE(trecho) e o RDE(total). O $\mathrm{RDE}$ (trecho) é utilizado para o cálculo de pequenas extensões nas quais o rio principal está sendo dividido. O índice RDE(total) é aplicado para toda a extensão do curso, da nascente até a foz do rio que se deseja verificar. O valor do $\mathrm{RDE}($ real), aquele que será utilizado na análise final acerca de influência tectônica, é dado pela divisão do valor do RDE(trecho) pelo valor do RDE(total) do curso que está sendo analisado.

O RDE(total) foi aplicado para o rio principal da bacia, desconsiderando a área referente ao açude Marés, devido à interferência antrópica, que interferiria nos resultados obtidos. Para a aplicação do RDE(trecho) foram definidos previamente três segmentos de 
proporções semelhantes ao longo do curso do rio principal, os quais atingem a extensão total de $7,40 \mathrm{~km}$ (Figura 4).

Figura 4 - Trechos escolhidos para o cálculo do RDE trecho, na bacia do rio Marés.

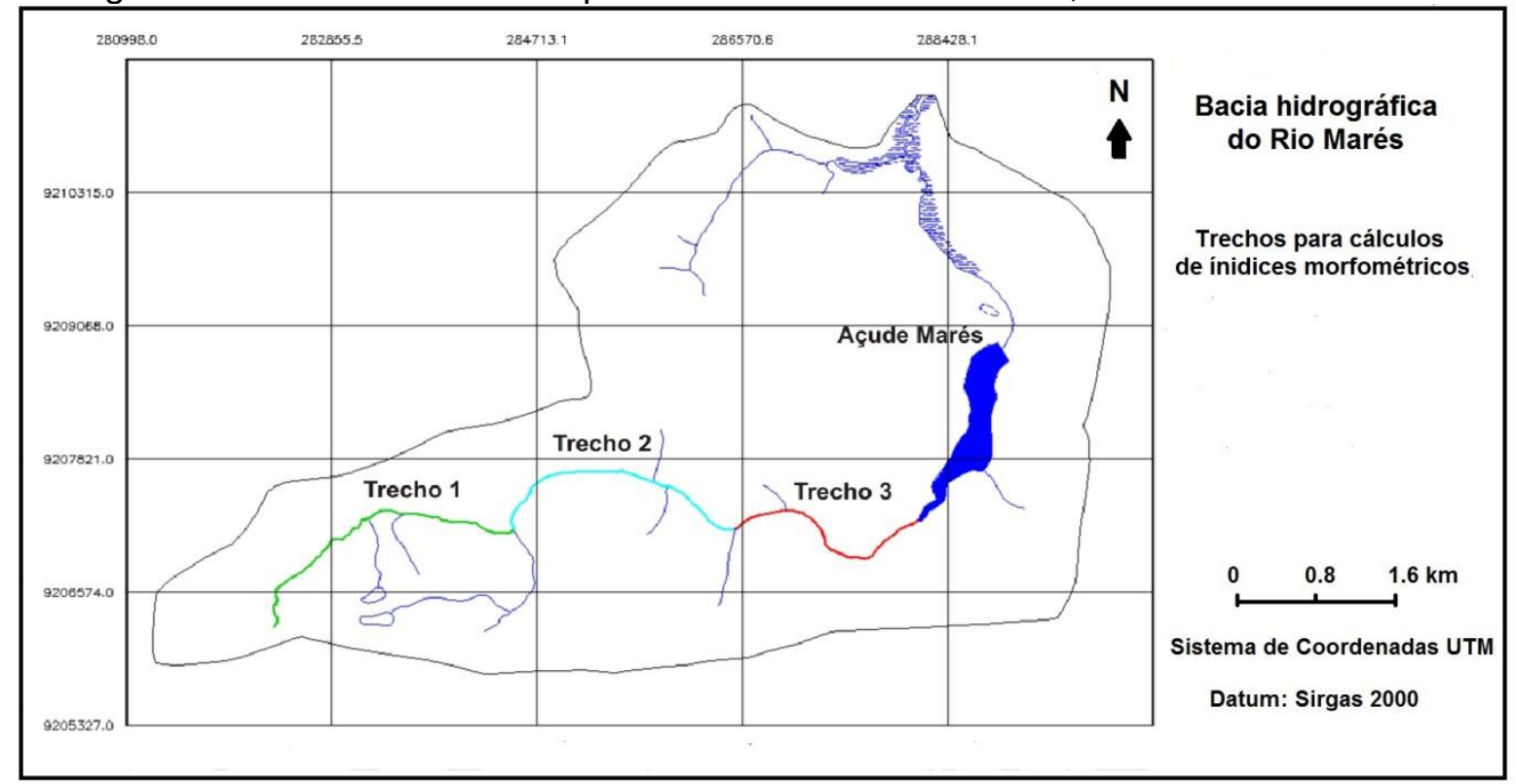

Dados: Elaborado a partir da vetorização da carta topográfica Santa Rita 1:25.000 (SUDENE,1974) e tratamento dos dados no SIG Spring 5.2.

Para avaliar os valores de RDE adotou-se como base o trabalho de Andrades Filho (2010), onde ele ressalta que os segmentos considerados anômalos são os que obtêm $\mathrm{RDE}$ (real) (RDE(trecho)/RDE(total)) maior ou igual a 2. Também foi consultado o trabalho de Sebeer e Gornitz (1983), onde eles apontam que, para o índice RDE maior que 2, existem duas categorias: as anomalias de $2^{\underline{a}}$ ordem, referentes aos índices compreendidos entre os limiares 2 a 10; e as anomalias de $1^{\text {a }}$ ordem, referentes aos valores iguais ou superiores a 10.

A obtenção do índice RDE por trechos apontou que todos os seguimentos previamente selecionados apresentam indícios de anomalias de drenagem, estando eles posicionados no alto, médio ou baixo curso do rio. A Tabela 2 mostra um resumo das variáveis morfométricas encontradas no curso total e nos seguimentos do rio Marés, bem como os resultados de RDE trecho, total e real, este último corresponde à efetivação da divisão entre os valores do $\operatorname{RDE}$ (trecho) e $\mathrm{RDE}$ (total).

O rio principal para o qual foi calculado $\operatorname{RDE}$ (total) apresentou um valor de 2,068, estando então dentro da classificação de anomalias de $2^{\mathrm{a}}$ ordem entre os limiares 2 a 10. Dos três seguimentos analisados, todos obtiveram resultados de RDE(real) altíssimos, que foram respectivamente os valores 13, 10 e 17, que de acordo com a classificação de Seeber 
e Gornitz (1983), representam anomalias de $1^{\text {a }}$ ordem com valores iguais ou superiores a 10.

Os resultados dos cálculos de $\mathrm{RDE}$ (total) e $\mathrm{RDE}$ (trecho) do curso do rio Marés apontam que o mesmo se encontra dentro do padrão anômalo, ou seja, maior que 2, e por se tratar de uma bacia que está situada predominantemente sobre uma mesma litologia sedimentos inconsolidados da Formação Barreiras -, presume-se que os altos valores de RDE estejam ligados à atividades de tectônica recente.

Tabela 2 - Variáveis Morfométricas do rio Marés

\begin{tabular}{c|c|c|c|c}
\hline Trechos & Rio Principal & Trecho 1 & Trecho 2 & Trecho 3 \\
\hline Cota Superior $(\mathrm{m})$ & 67 & 67 & 40 & 30 \\
\hline Cota Inferior $(\mathrm{m})$ & 20 & 40 & 30 & 20 \\
\hline $\begin{array}{c}\text { Diferença Altimétrica } \\
(\mathrm{m})\end{array}$ & 47 & 27 & 10 & 10 \\
\hline $\begin{array}{c}\text { Extensão do Trecho } \\
(\mathrm{m})\end{array}$ & - & 2858 & 2531 & 2013 \\
\hline Extensão Total $(\mathrm{m})$ & 7404 & 2858 & 5390 & 7403 \\
\hline RDE trecho & - & 27 & 21 & 36 \\
\hline RDE total & 2,068 & 2,068 & 2,068 & 2,068 \\
\hline RDE Real & 2,068 & 13 & 10 & 17 \\
\hline
\end{tabular}

Fonte: Pesquisa direta.

\section{Índice Razão Fundo Altura de Vale (RFAV)}

Este índice é sensível à morfologia de vales, visto que distingue vales que possuem superfície ampla no fundo ou em "U", de vales estreitos ou em "V". Os altos valores de RFAV são atribuídos, geralmente, a vales em forma de "U" e os baixos referem-se a vales em forma de "V", que indicam processos de incisão, e estes são comumente associados a soerguimentos tectônicos. Índices de RFAV menores que 1 são indicativos de áreas em soerguimento recente (SILVA et al., 2003).

O índice RFAV foi aplicado em três perfis da bacia do rio Marés, cortando paralelamente o rio principal em seu alto, médio e baixo curso. Esses perfis foram delimitados por dois divisores de água em lados antagônicos da bacia, tendo como valores de referência curvas de nível e pontos cotados (Figuras 5 e 6).

Como se pode constatar observando os perfis, o corte transversal feito da área direita para a esquerda da bacia mostram situações bem semelhantes, a morfologia tabular cortada pelo vale mais ou menos em "V", indicando processo de incisão no curso do rio.

Os resultados alcançados no cálculo do RFAV na bacia do rio Marés indicam forte influência de tectônica recente, como mostram os valores na Tabela 3, o perfil 1 obteve 0,92 e o perfil 2 obteve 0,74, apontando o possível soerguimento recente da área, tendo como valor acima de 1 somente o perfil 3, que foi o traçado à jusante do rio. Tais valores 
corroboram fortemente para a ideia de influência neotectônica na bacia estudada, que apesar de estar situada em uma área de baixas altitudes tem entalhado seu vale de forma significante.

Figura 5 - Perfis selecionados para o cálculo do índice RFAV na bacia do rio Marés.

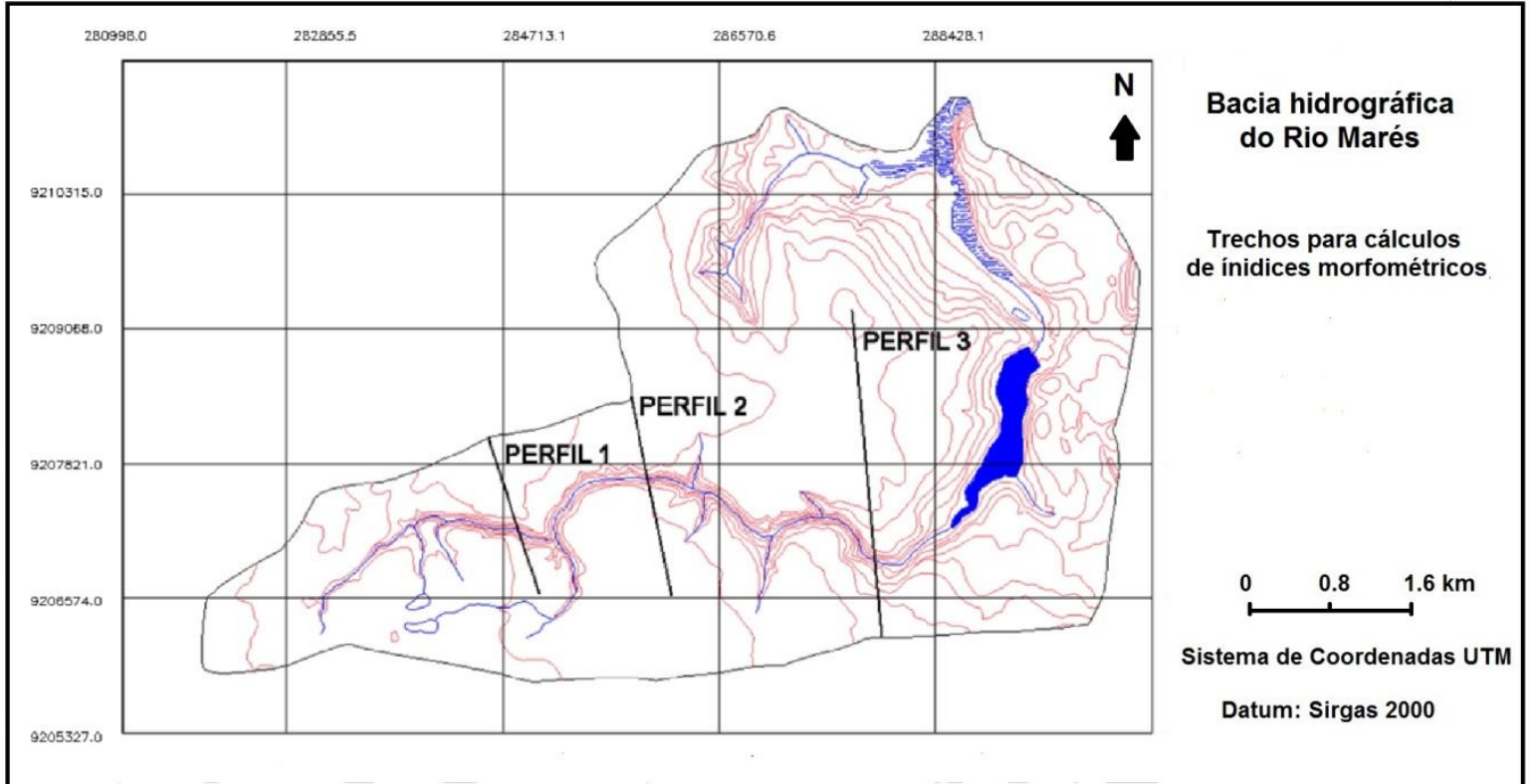

Dados: Elaborado a partir da vetorização da carta topográfica Santa Rita 1:25.000 (SUDENE,1974) e tratamento dos dados no SIG Spring 5.2.

Figura 6 - Perfis transversais dos pontos para onde foram calculados o RFAV.

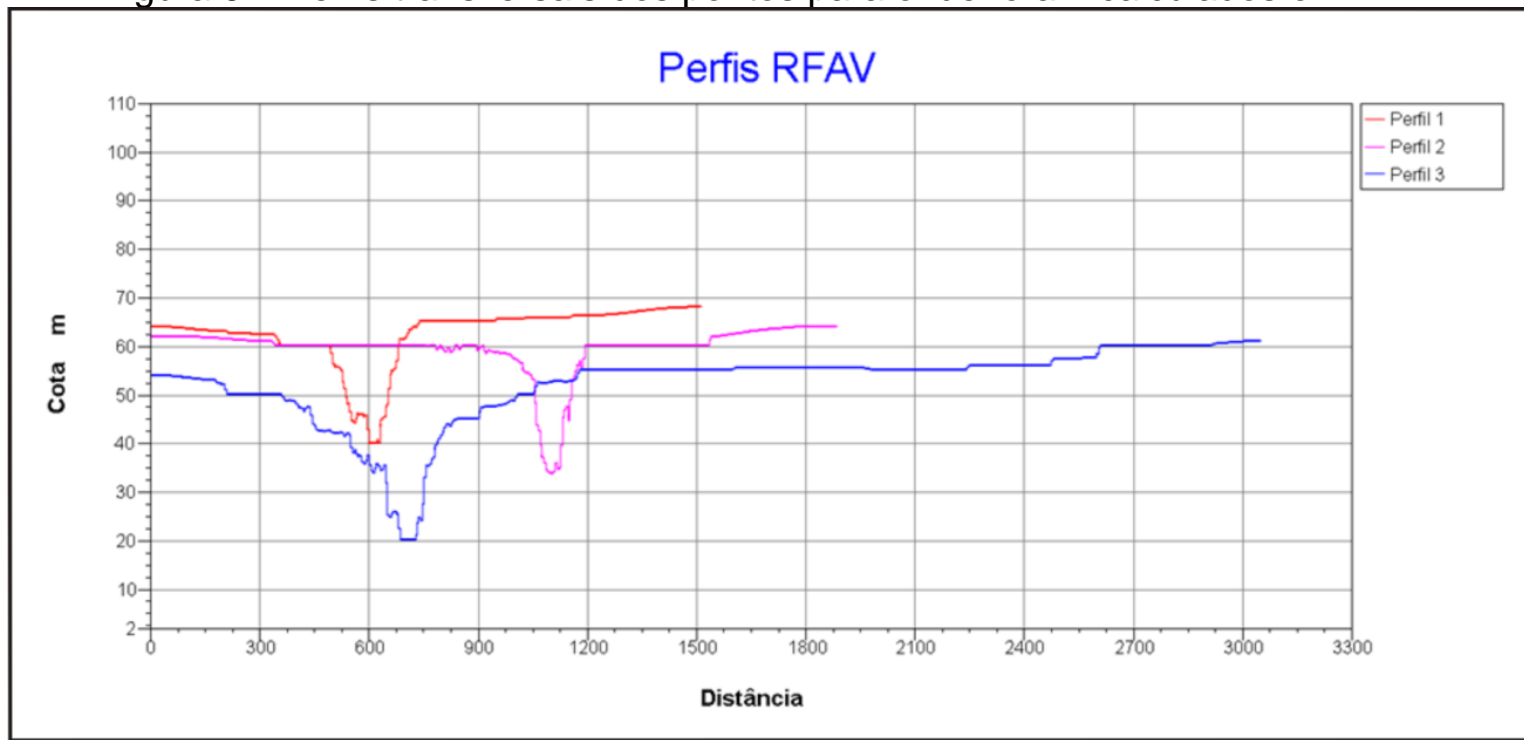

Dados: Elaborados a partir da vetorização da carta topográfica Santa Rita 1:25.000 (SUDENE 1974) e tratamento dos dados no SIG Spring 5.2. 
Tabela 3 - Valores para o cálculo do RFAV e resultados obtidos

\begin{tabular}{c|c|c|c|c|c}
\hline PERFIS & Vwf & Eld & Erd & Esc & RFAV \\
\hline Perfil 1 & $23,95 \mathrm{~m}$ & $68 \mathrm{~m}$ & $64 \mathrm{~m}$ & $40 \mathrm{~m}$ & 0,92 \\
\hline Perfil 2 & $21,47 \mathrm{~m}$ & $64 \mathrm{~m}$ & $62 \mathrm{~m}$ & $34 \mathrm{~m}$ & 0,74 \\
\hline Perfil 3 & $54,05 \mathrm{~m}$ & $54 \mathrm{~m}$ & $61 \mathrm{~m}$ & $20 \mathrm{~m}$ & 1,45 \\
\hline
\end{tabular}

Fonte: Pesquisa direta.

\section{Índice Fator de Assimetria (FA)}

Através das ferramentas de edição vetorial do Spring 5.2, foi possível delimitar tanto a área total da bacia quanto a margem direita da mesma. E, logo após, com a ferramenta operações métricas foi possível obter os valores de Ad (área da margem direita) e At (área total da bacia) (Tabela 4). Após os cálculos de área efetuou-se o FA, substituindo os valores encontrados na dada fórmula.

Tabela 4 - Valores obtidos para os cálculos do Fator Assimétrico do rio Marés

\begin{tabular}{ccc}
\hline Área do lado direito da bacia (Ad) & Área total da bacia (At) & Fator Assimétrico (FA) \\
\hline $13,166 \mathrm{~km}^{2}$ & $28,010 \mathrm{~km}^{2}$ & 47 \\
\hline & Fonte: Pesquisa direta.
\end{tabular}

O valor obtido no índice FA para a bacia do rio Marés foi inferior a 50 e, apesar de indicar um basculamento da margem direita da bacia, não sugere influência neotectônica, como ocorreu nos outros índices aplicados. A Figura 7 mostra uma escala de intensidade elaborada por Rubin (2003) para o FA, que indica intensidades classificadas em "muito, medianamente, pouco e pouquíssimo".

Figura 7 - Escala de intensidade para o AF.

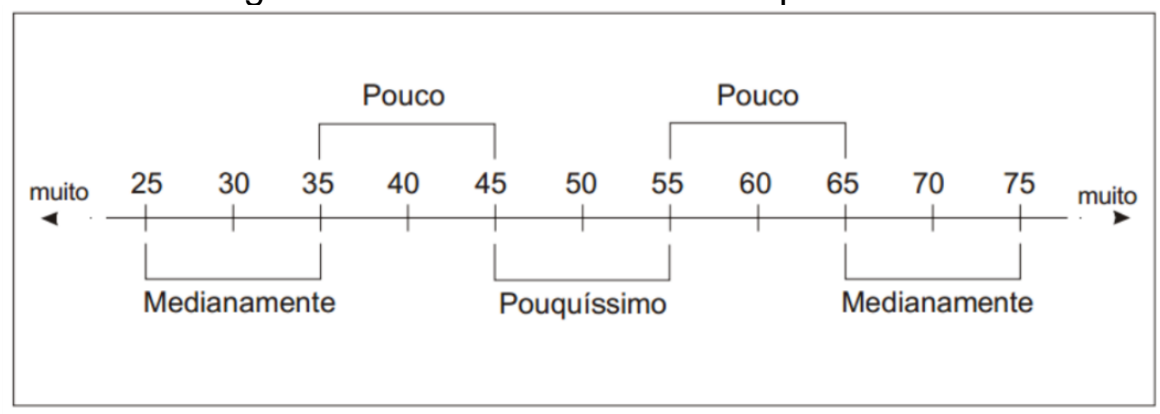

Fonte: Rubin 2003, 263.

O valor resultante do cálculo para a bacia (47) fica na classificação "pouquíssimo afetado por neotectônica", contrapondo-se aos demais resultados encontrados na análise da mesma. Entretanto, comprova o basculamento da margem direita da bacia, onde se 
encontram quase todos os afluentes da mesma e onde os cursos são mais expressivos, comprovado na análise dos materiais cartográficos e em trabalho de campo.

\section{CONCLUSÕES}

Pôde-se obter, através deste estudo, um melhor conhecimento da geomorfologia e morfometria da área. E por meio dos produtos cartográficos elaborados - cartas de altimetria e declividade, bem como a aplicação dos índices morfométricos (RDE, RFAV e FA), foi possível constatar a possível presença de atividades neotectônicas sobre a área em que se assenta a bacia em estudo, principalmente pelo altíssimo valor de RDE e seu grande entalhe, sugerindo a ocorrência de um basculamento recente.

Esses índices, pouco utilizados no Brasil, mostraram ser de grande valia em estudos neotectônicos, e devem ser levados em consideração em pesquisas semelhantes em outras áreas da costa paraibana, que é tão carente de estudos nesta linha de pesquisa.

Todos os dados obtidos com os levantamentos bibliográficos e cartográficos foram integrados através das técnicas de Geoprocessamento, que possibilitaram a visualização completa e em grande escala de detalhe da área e cruzaram grande quantidade de dados armazenados no banco de dados.

\section{REFERÊNCIAS}

ANDRADES FILHO, C. O. Análise morfoestrutural da porção central da Bacia Paraíba (PB) a partir de dados MDE-SRTM e ALOS-PALSAR FBD. 2010. 150f. Dissertação (Mestrado em Sensoriamento Remoto) - Instituto Nacional de Pesquisas Espaciais. São José dos Campos: Inpe, 2010.

ARAI, M. A grande elevação eustática do Mioceno e sua influência na origem do Grupo Barreiras. Geologia USP Série Científica, São Paulo, v. 6, n. 2, p. 1-6, 2006.

BARBOSA, M. E. F.; FURRIER, M. Análise de bacia hidrográfica como subsídio para detecção de neotectônica: estudo da bacia hidrográfica do rio Guruji, Litoral Sul do estado da Paraíba. Cadernos de Geociências, Salvador, v. 8, n. 1, p. 10-18, 2011.

CARRILHO, L. V. A. M.; SANTOS, K. M.; FILGUEIRA, H. J. A.; NEVES, C. A.; PEDROSA FILHO, L. A.; SILVA, T. C. Integrando informações para a gestão de restauração de rios: bacia do rio Marés no Litoral Sul Paraibano. Simpósio De Recursos Hídricos Do Nordeste, Anais... Salvador: ABRH, 2008.

CHRISTOFOLETTI, A. Geomorfologia. São Paulo: Edgard Blücher/EDUSP, 1980.

ETCHEBEHERE, M. L. C.; SAAD, A. R.; CASADO, F. C.; FULFARO, V. J.; PERINOTTO, J. A. J. 2004. Aplicação do índice Relação Declividade-Extensão (RDE) na bacia do Rio do Peixe (SP) para detecção de deformações neotectônicas. Revista de Geociências USP, São Paulo, v. 4, p. 43-56.

ETCHEBEHERE, M. L. C.; SAAD, A. R.; SANTONI, G. C.; CASADO, F. C.; FULFARO, V. J. Detecção de prováveis deformações neotectônicas no vale do Rio do Peixe, região ocidental paulista mediante aplicação de índices RDE (Relação Declividade-Extensão) em segmentos de drenagem. Revista de Geociências USP, São Paulo, v. 25, p. 271-289, 2006. 
HACK, J. T. Stream-profile analysis and stream gradient index. U.S. Geol. Survey, Jour. Research, v. 1, n. 4, p. 421-429, 1973.

HERZ, R.; DE BIASI, M. Critérios e legendas para macrozoneamento costeiro. Ministério da Marinha/Comissão Interministerial para os Recursos do Mar. Brasília: MM, 1989.

MARTINEZ, M. Aplicação de parâmetros morfométricos de drenagem na bacia do rio Pirapó: o perfil longitudinal. 96 p. Dissertação (Mestrado em Geografia) -Departamento de Geografia do Centro de Ciências Humanas, Letras e Artes. Maringá: da Universidade Estadual de Maringá, 2005.

MELO, A. S. T. Paraíba: desenvolvimento econômico e a questão ambiental. João Pessoa: Editora Grafset, 2003.

RUBIN, J. C. R. Sedimentação quaternária, contexto paleoambiental e interação antrópica nos depósitos aluviais do Alto rio Meia Ponte - Goiás - GO. Tese (Doutorado) - Universidade Estadual Paulista, Instituto de Geociências e Ciências Exatas. Rio Claro: Universidade Estadual Paulista, 2003.

SEEBER, L.; GORNITZ, V. River profiles along the Himalayan arc as indicators of active tectonics. Tectonophysics, Amsterdam, v. 92, p. 335-367, 1983.

SILVA, A. M.; SCHULZ, H. E.; CAMARGO, P. B. Erosão e hidrossedimentologia em bacias hidrográficas. São Carlos: RIMa, 2003.

SUDENE. Superintendência de Desenvolvimento do Nordeste. Folha Santa Rita SB. 25-YC-III-1-SO (1:25.000). Recife. Carta Topográfica, 1974.

\footnotetext{
${ }^{1}$ Universidade Federal da Paraíba (UFPB). Cidade Universitária, s/n - Castelo Branco, João Pessoa PB, 58051-900. mires.ufpb@gmail.com

${ }^{2}$ Universidade Federal da Paraíba (UFPB). Cidade Universitária, s/n - Castelo Branco, João Pessoa PB, 58051-900. max furrier@hotmail.com
} 